\title{
Neuropsychological and Glucose Metabolic Profiles in Asymmetric Parkinson's Disease
}

\author{
Erich Mohr, Ulrike M. Mann, Robert S. Miletich, Margaret Sampson, Terry E. Goldberg, \\ J. David Grimes and Thomas N. Chase
}

\begin{abstract}
Patients with predominantly unilateral parkinsonian signs may provide a unique opportunity to evaluate the cerebral representation of cognitive functions characteristically affected in idiopathic Parkinson's disease. Twenty hemiparkinsonian patients (ten left and ten right) and 10 healthy controls, matched for age and education, were studied with neuropsychological tests and positron emission tomography. Both right and left hemiparkinsonians evidenced impairments in visuospatial and verbal episodic memory function, but had no deficits in executive abilities, compared to controls. None of the neuropsychological test scores distinguished right from left hemiparkinsonians. Glucose metabolic profiles were identical for the three groups in all cortical areas assessed; in the subcortex however, lenticular hypermetabolism contralateral to the predominant side of motor involvement was evident in the left hemiparkinsonian group. Correlational analysis revealed that higher glucose metabolic rates in the basal ganglia of these hemiparkinsonians were associated with lower visuospatial test scores. In frontal and parietal cortex, decreasing glucose metabolism was positively associated with neurobehavioral function; in temporal cortex, measures of attention and memory decreased with increasing glucose metabolic rates.
\end{abstract}

\begin{abstract}
RÉSUMÉ: Profil neuropsychologique et profil du métabolisme du glucose dans la maladie de Parkinson asymétrique. Les patients dont les signes parkinsoniens sont à prédominance unilatérale offrent une occasion unique d'évaluer la représentation cérébrale des fonctions cognitives qui sont atteintes de façon caractéristique dans la maladie de Parkinson idiopathique. Vingt hémiparkinsoniens (dix avec signes à l'hémicorps gauche et dix à l'hémicorps droit) et dix contrôles sains, appariés pour l'âge et le niveau d'éducation, ont été étudiés au moyen d'épreuves neuropsychologiques et de la tomographie à émission de positions. Les hémiparkinsoniens gauches et droits avaient une atteinte de la fonction mnésique épisodique visuospatiale et verbale, sans déficit des capacités d'exécution, comparés aux contrôles. Aucun des scores des épreuves neuropsychologiques ne distinguait les hémiparkinsoniens droits des hémiparkinsoniens gauches. Les profils du métabolisme du glucose étaient indentiques dans les trois groupes dans troutes les zones corticales étudiées; dans le sous-cortex cependant, il y avait évidence d'hypermétabolisme lenticulaire contralatéral au côté où prédominaient les signes d'atteinte motrice dans le groupe d'hémiparkinsoniens gauches. Une analyse de corrélation a révélé que les taux plus élevés du métabolisme du glucose dans les ganglions de la base de ces hémiparkinsoniens étaient associés à des scores plus bas aux épreuves visuospatiales. Dans le cortex frontal et pariétal, une baisse du métabolisme du glucose était associée positivement à la fonction neurobéhaviorale; dans le cortex temporal, les mesures de l'attention et de la mémoire diminuaient avec des taux croissants de métabolisme du glucose.
\end{abstract}

Can. J. Neurol. Sci. 1992; 19: 163-169

Significant changes in cognition and memory are now recognized as an important feature of idiopathic Parkinson's disease. ${ }^{1-6}$ Specifically, this illness has been associated with deficits in executive function, including poor problem solving capabilities produced by slowness and impaired strategy and planning. ${ }^{7.8}$ Deficits in visuospatial cognition ${ }^{3,4,9,10}$ and memory ${ }^{1,11-13}$ particularly episodic memory (context-bound knowledge) ${ }^{14}$ also form an integral part of the cognitive sequelae of this disorder.

Parkinson's disease, in contrast to most other neurodegenerative disorders, not infrequently presents with symptoms largely or exclusively limited to one side. ${ }^{15}$ This asymmetry presumably reflects differential involvement of nigrostriatal dopaminergic projections and other neuronal systems known to degenerate in this disorder. ${ }^{15-17}$ Whether this asymmetric involvement affects cognitive function, has, however, remained relatively uncertain (e.g. ${ }^{18-22}$ ).

Positron emission tomography has been used to investigate asymmetries of central nervous system (CNS) function in Parkinson's disease (e.g. ${ }^{23.24}$ ). However, no attempts have yet been made to systematically explore symptomatic lateralization in hemiparkinsonians both with neuropsychological testing and

From the Institute of Mental Health Research (E.M., M.S.); Loeb Institute for Medical Research (J.D.G.), University of Ottawa, Ottawa; University of Hamburg, University Hospital Eppendorf, Department of Neurology, Hamburg, Federal Republic of Germany (U.M.M.); National Institutes of Health. National Institute of Neurological Disorders and Stroke, Bethesda, Maryland (R.S.M.); National Institutes of Health, National Institute of Mental Health, St. Elisabeth Hospital, Washington, D.C. (T.E.G.)

Received July 2, 1991. Accepted in final form December 5, 1991

Reprint requests to: Dr. Erich Mohr, Institute of Mental Health Research, 1145 Carling Avenue, Ottawa, Ontario, Canada K1Z 7K4 
glucose metabolic profiles and to examine a possible relationship between these two assessment domains.

Parkinsonian patients with motor involvement restricted predominantly to one side and matched control subjects were therefore studied both neuropsychologically and with positron emission tomography (PET).

\section{MethodS}

Twenty patients with idiopathic Parkinson's disease (15 men and 5 women), with 10 patients in stage $I$ of the modified Hoehn and Yahr scale ${ }^{15.25}$ and 10 in stage II while unmedicated, consented to participate in this study after full disclosure of potential risks and benefits. Ten patients (mean \pm SEM and range age $61 \pm 3,44-75$ years) evidenced motor involvement primarily on the right side, with half the group showing motor signs only on the right (Hoehn and Yahr stage I) and the other half demonstrating motor signs predominantly on the right (Hoehn and Yahr stage II). The 10 remaining parkinsonians (age $55 \pm 1$, range 35 71 years) had motor symptoms predominantly on the left side, again with 5 with left sided motor involvement only (Hoehn and Yahr stage I) and 5 with predominantly left-sided Parkinsonian motor signs (Hoehn and Yahr stage II). Both patient groups had a mean duration of symptoms of $4 \pm 1$ years, with a range of 1-10 years for the right hemiparkinsonians and $1-15$ years for the left patients. Neither age, education or age at disease onset differed between the 2 patient groups (Table 1). Ten neurologically healthy subjects ( 7 men and 3 women) matched for age $(60 \pm 4$, range $36-73)$ and education ( $17 \pm 1$, range $12-20)$ served as controls. None of the patients or controls received centrally active medications, including anticholinergics or deprenyl, for a least 4 weeks prior to neuropsychological testing or PET scanning, except for levodopa treatment for the parkinsonian patients, which was discontinued approximately 12 hours before testing and reinstated immediately following each procedure.

General intellectual and memory function was assessed with the Wechsler Adult Intelligence Scale-Revised (WAIS-R) ${ }^{26}$ and the Wechsler Memory Scale (WMS). ${ }^{27}$ Dementia presence and severity was evaluated with the Mattis Dementia Rating Scale. ${ }^{28}$ In addition, the following neuropsychological tests were administered to examine executive function, visuospatial skills and memory: Wisconsin Card Sort Test, ${ }^{29}$ Embedded Figures Test, ${ }^{30}$
Benton Visual Retention Test, ${ }^{31}$ Mosaic Comparison Test, ${ }^{32}$ Raven's Progressive Matrices, ${ }^{33}$ Street Map, ${ }^{34}$ Rey Osterrieth Complex Figure ${ }^{35,36}$ and Sentence Memory. ${ }^{37}$ All tests were given without time limits and inaccuracies related to tremor were ignored. Assessment of patients' mood state with the Beck depression inventory ${ }^{38}$ revealed no evidence of significant depression (left patient group mean \pm SEM score of $8 \pm 1$, right $10 \pm 2$ and controls $5 \pm 1$ ).

Positron emission tomography, performed within 12 weeks of neuropsychological testing, was conducted in a quiet, dimly lit room under resting conditions, with subjects' eyes and ears plugged. ${ }^{39}$ All subjects had fasted for at least 5 hours prior to the procedure. $\left[{ }^{18} \mathrm{~F}\right]$ fluorodeoxyglucose (FGD; $5 \mathrm{mCi}$ ) was administered intravenously. Serial blood samples were taken from an arterialized vein, for the determination of plasma glucose and FDG levels. Scanning was performed with the Neuro-PET camera, which has a spatial resolution of 6-7 mm Full Width Half Maximum (FWHM) in plane and $10-13 \mathrm{~mm}$ FWHM in axial direction. From 4 rings of detectors, seven contiguous slices were reconstructed. Corrections for scatter, random coincidences and calculated attenuation were applied. The net sensitivity (less scatter) for all slices was approximately 400,000 counts per $\mathrm{sec} / \mu \mathrm{Ci} / \mathrm{ml}^{40.41}$ The scan plane was parallel to the canthomeatal line. Scanning commenced 30 minutes after isotope injection. Six scans each of 7 minutes duration, were obtained for a full survey of the brain.

A region of interest template consisting of 152 circular regions (size: $48 \mathrm{~mm}^{2}$ ) at 7 different levels was employed with each region placed on a predefined anatomic structure at its local metabolic maximum. These 7 levels were anatomically determined based on landmarks in the FDG-PET images. They corresponded to levels $26,42-46,63-70,74-78,86-89,94$ and 97 in the brain atlas of Aquilonius and Eckernas. ${ }^{42}$ These levels were selected to allow sampling of brain metabolism (calculated using the Sokoloff model with the Brooks modification ${ }^{43}$ ) in different structures along the intracranial neuraxis. Regions were pooled as arithmetic means based on anatomic structure. Values were derived for mesial and lateral cortex (frontal, temporal and parietal lobes) and the basal ganglia (caudate head and lenticular nuclei) for each hemisphere. These values were then normalized to the whole brain metabolism by dividing each by the whole

Table 1: Clinical Characteristics of the Study Subjects

\begin{tabular}{|c|c|c|c|}
\hline & $\begin{array}{l}\text { Hemileft Patients } \\
(\mathbf{N}=\mathbf{1 0})\end{array}$ & $\begin{array}{l}\text { Hemiright Patients } \\
(\mathbf{N}=\mathbf{1 0})\end{array}$ & $\begin{array}{c}\text { Normal Controls } \\
(\mathbf{N}=10)\end{array}$ \\
\hline $\begin{array}{l}\text { Age at Disease Onset } \\
\text { Symptom Duration (Years) } \\
\text { Age at Testing } \\
\text { Education (Years) }\end{array}$ & $\begin{array}{r}50.6 \pm 4.3 \\
4.3 \pm 1.3 \\
54.9 \pm 4.0 \\
16.2 \pm 1.0\end{array}$ & $\begin{array}{r}56.6 \pm 3.7 \\
4.4 \pm .9 \\
61.0 \pm 3.4 \\
16.1 \pm .8\end{array}$ & $\begin{array}{l}59.8 \pm 3.5 \\
16.9 \pm 1.0\end{array}$ \\
\hline $\begin{array}{l}\text { Wechsler Tests: } \\
\text { Verbal IQ } \\
\text { Performance IQ } \\
\text { Full Scale IQ } \\
\text { Memory Quotient }\end{array}$ & $\begin{array}{l}122.5 \pm 4.8 \\
105.7 \pm 3.7^{* * *} \\
116.5 \pm 4.5^{*} \\
118.6 \pm 5.8\end{array}$ & $\begin{array}{l}118.0 \pm 3.1^{*} \\
108.1 \pm 4.6^{* *} \\
114.9 \pm 3.6^{* *} \\
125.4 \pm 4.4\end{array}$ & $\begin{array}{l}127.5 \pm 3.2 \\
124.6 \pm 3.2 \\
129.7 \pm 3.0 \\
131.6 \pm 4.4\end{array}$ \\
\hline Mattis Dementia Rating Scale & $141.3 \pm 1.0$ & $141.2 \pm 1.0$ & $142.2 \pm$ \\
\hline
\end{tabular}

Mean \pm Standard Error of the Mean (S.E.M.)

* Group differs from controls at $p<.05$

** Group differs from controls at $p<.01$

$* * *$ Group differs from controls at $\mathrm{p}<.001$ 
brain value. Whole brain metabolism was determined by averaging the whole slice values from the 4 most superior slices of the template using an edge finding routine to define the external cortical boundary based on a seed value equal to $50 \%$ of the maximum cortical value. The seven slices chosen for detailed region of interest analysis were confined to the time window between 40 and 65 minutes after FDG administration. Values were derived from this narrow window to ensure comparability.

Data were analyzed with standard multivariate analysis of variance procedures and where appropriate, with correlational measures, corrected for multiple comparisons.

\section{Results}

Global intellectual function, as measured by WAIS-R Full Scale IQ, was significantly lower in both right and left hemiparkinsonian patient groups compared to controls $(p<.05$, Table 1). Verbal intellectual function (WAIS-R Verbal IQ,
Table 1), was decreased in right, but not left hemiparkinsonians relative to controls. Items requiring psychomotor speed and visuospatial integration placed both hemiparkinsonian groups significantly lower than controls (WAIS-R Performance IQ, $p<.01$, Table 1). Neither patient group showed any evidence of dementia (Mattis Dementia Rating Scale, Table 1). No significant differences emerged between left and right hemiparkinsonian patients on any of these global measures.

Global memory function, as measured by the WMS Memory Quotient (MQ) evidenced no statistically significant decrement in left and right hemiparkinsonian patients compared to controls (Table 1). However, memory tasks requiring sustained effort and attention (Logical Memory Subtest, WMS), were impaired in both hemiparkinsonian patient groups relative to controls (Figure 1). Performance on memory tests with relatively less task demand (Visual Reproduction and Paired Associate Learning, WMS, as well as Sentence Memory), on the other hand, was not comprised in these patients. No differences

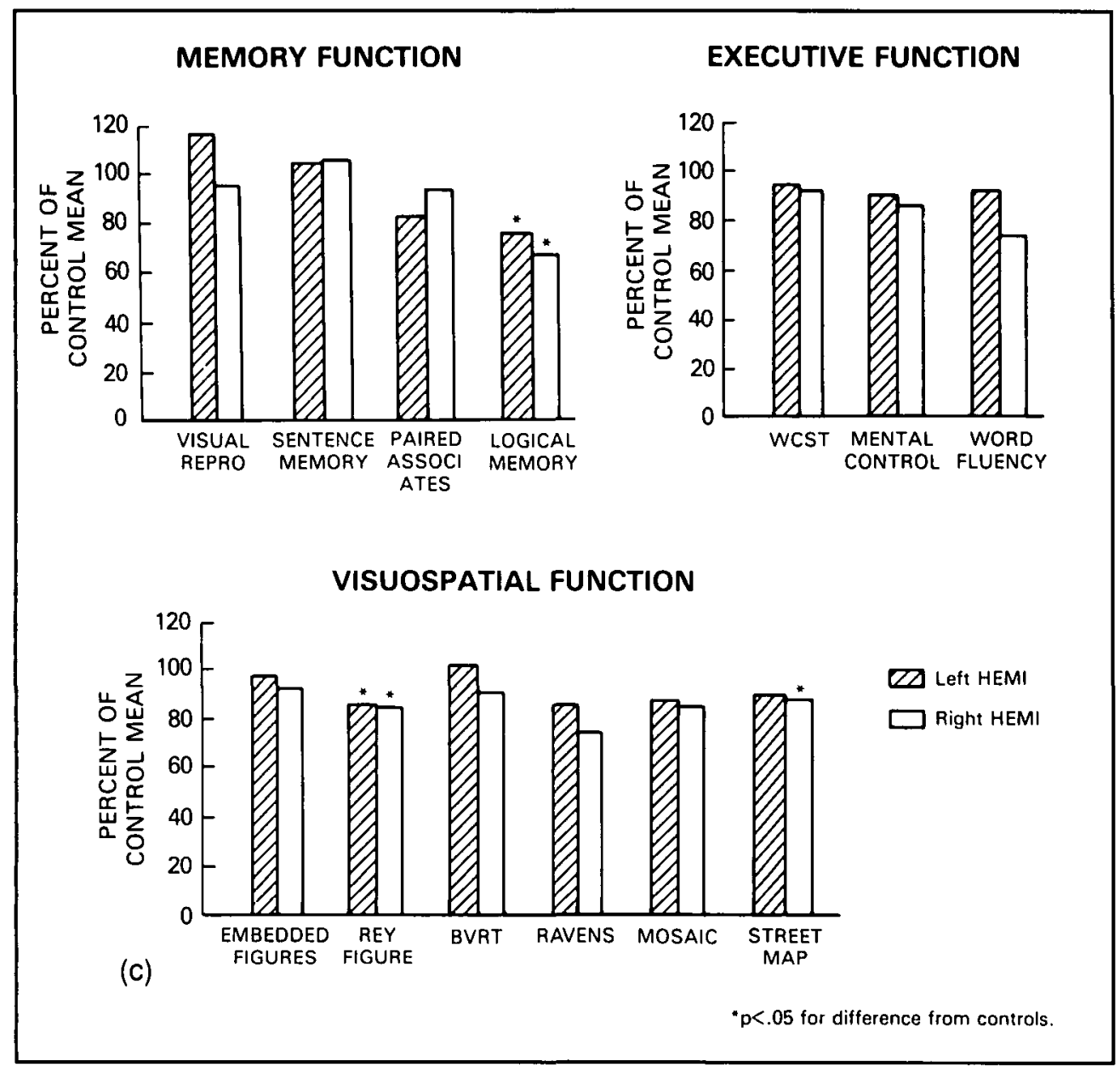

Figure I - Neuropsychological Performance of Hemiparkinsonian patients expressed as percentage of normal control values.* Memory Function: Visual Reproduction** $11 \pm 1.0$. Sentence Memory $19 \pm 0.5$, Paired Associates 16 \pm 1.0 . Logical Memory** $11 \pm 0.8$; Executive Function: Wisconsin Card Sorting Test (WCST) Perseverative Errors $1 / \pm 2.0$, Mental Control $8 \pm 0.3$, Word Fluency $36 \pm 0.3$; Visuospatial Function: Embedded Figures $18 \pm 1.0$, Rey Figure $34 \pm 0.5$, Benton Visual Retention Test (BVRT) $7 \pm 0.4$, Raven's Progressive Matrices $48 \pm 4.0$. Mosaic Comparison Test $57 \pm 7.0$. Street Map $15 \pm 0.5$.

* Represented are mean control performance levels \pm S.E.M.

** Subtests of the Wechsler Memory Scale 
between left and right hemiparkinsonian patients could be ascertained with any of these memory measures (Table 1; Figure 1a).

Executive function, as assessed by Mental Control (WMS), Wisconsin Card Sorting Test (perseverative errors) and Word Fluency (Mattis Dementia Rating Scale) was well preserved in these hemiparkinsonian patients. No systematic differences were evident between left and right hemiparkinsonian patient groups (Figure lb).

Visuospatial tasks of a complex nature evidenced consistent deficits in both left and right hemiparkinsonian patients compared to controls (Rey Complex Figure; Figure 1c). Right/left orientation was impaired in right but not left hemiparkinsonian patients relative to control performance (Street Map; Figure lc). None of the less complex tests of visuospatial function (Mosaic Comparison Test, Embedded Figures Test and Raven's Progressive Matrices) revealed any evidence of impairment in either of the hemiparkinsonian groups. No consistent group differences were evident between left and right hemiparkinsonians on any of the visuospatial tasks (Figure 1c).

Glucose metabolic profiles in cortex (frontal, temporal and parietal regions), failed to indicate any global hemispheric differences between left and right hemiparkinsonians or any differences between patients and controls (Table 2). In the basal ganglia however glucose metabolic profiles were more distinctive. Left hemiparkinsonians evidenced consistent hypermetabolism compared to controls in the right lenticular nucleus (Table 2). Further analysis indicated that these changes occurred predominantly in the posterior lenticular region. Left hemiparkinsonians $(1.63 \pm .05)$ showed markedly increased metabolism compared

Table 2: Glucose Metabolic Index (GMI)' for Each Region in Left and Right Hemiparkinsonian Patients and in Normal Controls

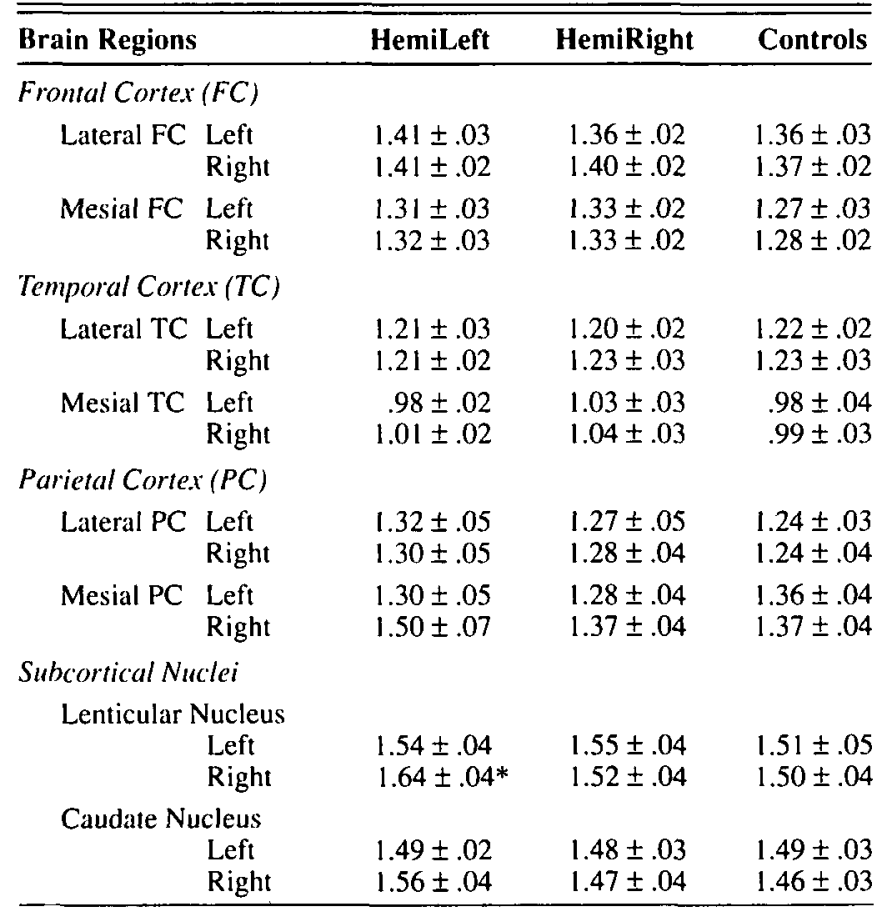

${ }^{\prime} \mathrm{GMI}=$ regional glucose utilization rate/whole brain glucose utilization rate

Mean \pm S.E.M.

$* p<.05$ Difference from controls to patients with predominant right-sided motor signs $(1.45 \pm .04 ; p<.01)$ and controls $(1.44 \pm .04 ; p<.01)$ in the right posterior lenticular nucleus. Right hemiparkinsonian metabolism in the left posterior lenticular nucleus (1.52 \pm .05 ) suggested an increase compared to controls (1.45 \pm .04$)$, but failed to reach statistical significance; no additional differences emerged when these values were compared to those of left hemiparkinsonians $(1.48 \pm .04)$. No statistical differences emerged in the areas comprising the anterior lenticular nucleus. No other regions in the subcortical area evidenced marked differences between groups.

Glucose metabolic profiles in cortex and neuropsychological test results (represented by hemisphere and collapsed across the two hemiparkinsonian groups) revealed certain significant associations in those with hemiparkinson's disease. Decreasing glucose metabolic rates in cortex were associated with lower verbal, visuospatial and executive function tests in frontal and parietal cortex (Table $3, \mathrm{r}>.5, \mathrm{p}<.01$ ). In temporal cortex, variables involving attention and memory evidenced negative correlations with glucose metabolism (Table $3, r>.5, p<.01$ ) in these hemiparkinsonian patients.

In subcortical areas, increased glucose metabolic rates correlated significantly with lower visuospatial test scores in caudate nucleus (Raven's Progressive Matrices, left side, $r>.5, p<.01$, Street Map, $r>.5, p<.01$ ) and in the lenticular nucleus (Mosaic Comparisons, left side, $r>.6, p<.01$ ). Logical memory (memory for a prose passage) was positively correlated with glucose metabolic rates in the left caudate region $(r>.5, p<.01)$. No

Table 3: Correlations of Neuropsychological Tests and Cerebral Glucose Metabolic Regions

\begin{tabular}{|c|c|c|}
\hline Brain Regions & Left Hemisphere & Right Hemisphere \\
\hline \multicolumn{3}{|l|}{ Frontal Cortex $(F C)$} \\
\hline Lateral FC & $\begin{array}{l}\text { Information' } \\
\text { Picture Completion' } \\
\text { Vocabulary' }\end{array}$ & Vocabulary' \\
\hline Mesial FC & Similarities ${ }^{1}$ & $\begin{array}{l}\text { Paired Associates }{ }^{2} \\
\text { WCST (Perseverations) }^{4}\end{array}$ \\
\hline \multicolumn{3}{|l|}{ Temporal Cortex (TC) } \\
\hline Lateral TC & $\begin{array}{l}\text { Initiation } \\
\text { Digits Backwards } \\
\text { Di.4 }\end{array}$ & \\
\hline Mesial TC & & 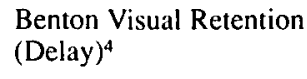 \\
\hline \multicolumn{3}{|l|}{ Parietal Cortex $(P C)$} \\
\hline Lateral PC & Digits Backwards ${ }^{2}$ & Digits Backwards ${ }^{2}$ \\
\hline Mesial PC & Digits Backwards ${ }^{2}$ & Logical Mem. (Delay) ${ }^{2}$ \\
\hline \multicolumn{3}{|l|}{ Subcortical Nuclei } \\
\hline \multicolumn{3}{|c|}{ Lenticular Nucleus Mosaic Comparisons ${ }^{4}$} \\
\hline Caudate Nucleus & \multicolumn{2}{|c|}{$\begin{array}{l}\text { Raven's Progressive Matrices }{ }^{4} \\
\text { Street Map } \\
\text { Logical Mernory }{ }^{2}\end{array}$} \\
\hline
\end{tabular}

Represented are tests and brain regions which correlate significantly at $r>.52, p<.01$

( $p$ level set at .01 to correct for multiple comparisons)

'Subtest of the Wechsler Adult Intelligence Scale - Revised

${ }^{2}$ Subtest of the Wechsler Memory Scale

${ }^{3}$ Subtest of the Mattis Dementia Rating Scale

${ }^{4}$ Negative correlation 
other brain region and neuropsychological test results evidenced additional significant associations.

\section{Discussion}

Observed differences in intellectual function (WAIS-R IQ scores) between hemiparkinsonians and controls may in part reflect the typical bradykinesia associated with this disorder. ${ }^{7}$ The relatively lower verbal IQ of right but not left hemiparkinsonians, compared to controls could reflect lateralized cortical hypofunction. However, the magnitude of this side to side difference was not sufficient to differentiate right from left hemiparkinsonian patients.

Global memory function (MQ) on the other hand remained relatively intact in both of these patient groups, even though memory is generally reported deficient in Parkinsonians. ${ }^{4.12 .13 .44}$ However, when distinguishing between the amount of effort required for task performance, a well established pattern (e.g. ${ }^{4.14}$ ), emerged: Those episodic memory items (tasks dated in time and place) requiring a relatively high degree of effort (e.g. recall of a complex piece of prose, Logical Memory) evidenced comparable impairment in both patient groups, while those with more moderate task demands (reproduction of a simple geometric pattern, Visual Reproduction and memory for meaningful sentences, (Sentence Memory)) were performed without deficiencies. Based on these observations, global indices of memory function like the MQ may be too insensitive to mark relatively circumscribed memory impairments.

Tests of executive function failed to reveal any compromise in hemiparkinsonians. Loss of executive abilities tends to be a common finding in those with Parkinson's disease (e.g. ${ }^{8.45 .46}$ ). Nevertheless, a recent report on cognitive disability in a group of Parkinsonians who continued to function successfully in intellectually demanding senior positions, who came to clinical attention solely for management of their motor disability, also failed to display any disability in that sphere. ${ }^{9}$ As a consequence, deficits in executive function do not appear to be consistent cognitive sequelae of Parkinson's disease.

Visuospatial tasks on the other hand, showed markedly lower performance for both patient groups compared to controls, but did not distinguish left from right hemiparkinsonians. Deficits were limited to the most demanding visuospatial task (ReyOsterrieth Figure), extending perhaps the concept of effort from memory 14 to visuospatial function in Parkinson's disease. Right/left orientation, which does not easily fit the effortful/noneffortful model yielded more puzzling results. Right hemiparkinsonians were impaired relative to controls, but those with predominantly left motor involvement were not. The functional significance of this finding is unclear. A previous report indicated only visuospatial impairment in a group of patients with predominantly right sided motor symptoms, while those with left symptoms were impaired both with respect to visuospatial function, memory and overall dementia score. ${ }^{21}$ Subsequent studies were more equivocal. ${ }^{18-20,47}$ Two of these ${ }^{20.47}$ asserted that neuropsychological performance differed as a function of side of maximal motor involvement. Patients with signs lateralized to the right were reportedly more impaired on dominant hemisphere function (e.g. WAIS verbal subtests ${ }^{47}$ and serial digit learning, confrontation naming and verbal associative fluency ${ }^{20}$ ). Conversely, it was contended that those with predominantly left- sided involvement evidenced mild left hemispatial neglect, ${ }^{47}$ but showed no differences on tests of non-dominant hemisphere function. Two subsequent studies failed to differentiate right from left hemiparkinsonians on neuropsychological grounds. 18.19 $^{\text {1 }}$ Results here would indicate that with the exception of a global measure of verbal function (WAIS-R Verbal IQ consistently decreased in right hemiparkinsonians compared to controls) and a single test of visuospatial function (right/left orientation worse compared to controls in right hemiparkinsonians), no differential features are present.

Glucose metabolic profiles were consistent with the neurobehavioral observations in failing to differentiate right from left patient groups. Different from the neuropsychological parameters, measures of cortical glucose metabolic activity did not discriminate between patients and controls. This could point to a relatively greater role of subcortical mechanisms in specific cognitive failure in Parkinson's disease then documented to date. In the basal ganglia, hemiparkinsonian patients did evidence some characteristic changes as a function of side of maximal motor involvement, particularly in the lenticular nucleus. However, statistical significance was limited to left hemiparkinsonians compared to controls with only a trend evident with reversed involvement for those with right-sided motor symptoms, presumably due to small sample size. Interestingly, in both cases the ipsilateral rates in glucose metabolism were virtually identical to those of controls. The functional significance of this observation may be related to the hypothesis that cholinergic and dopaminergic systems in basal ganglia are mutually antagonistic. ${ }^{48}$ Higher glucose metabolic activity on the side contralateral to maximal motor involvement might therefore reflect lower dopaminergic function coupled with acetylcholine hyperactivity, leading to lateralized increases in glucose metabolism.

The relative absence of differential patterns in neuropsychological and glucose metabolic profiles in cortex may reflect, in addition to the importance of subcortical mechanisms, a particular pattern of transmitter involvement. It is now well established that even mild Parkinsonian signs are associated with a disproportionate loss of striatal dopamine neurons. In fact, approximately $80 \%$ neuronal loss has to occur before the disease presents clinically. ${ }^{49}$ The differences in striatal dopamine between right and left hemiparkinsonian patients might well be small while showing markedly different clinical manifestations in motor function. However, at autopsy, dopamine levels in striatum reportedly exceed those in cortical areas by a factor of $1: 30,{ }^{50}$ potentially minimizing functional side to side differences. If dopamine loss is indeed the critical event, it is hardly surprising that neuropsychological parameters and cortical glucose metabolic parameters failed to differentiate consistently between these two patient groups.

Examination of correlational profiles (neuropsychological test results and glucose metabolism) underscored the notion of specific effects of transmitter loss. Neurobehavioral measures in frontal and parietal cortex decreased with glucose metabolic activities, including perseverative errors on the Wisconsin Card Sorting Test, where increasing numbers reflect poorer performance. The fact that correlational patterns did not emerge as a function of dominant (verbal) and non-dominant (non-verbal) tasks in the right and left hemisphere, emphasizes the contention that functional hemispheric lateralization is not absolute. This 
correlational pattern in frontal and parietal areas could involve decreased catecholaminergic activity, precipitated in part by the breakdown in striatal function in these patients. The consistently negative correlation between glucose metabolism and items involving memory and attention in temporal cortex is more difficult to interpret. One might speculate that this could reflect specific, circumscribed cholinergic hyperactivity in the temporal lobe, including the hippocampus, compensating for compromised function in the subcortical pathways. The lack of evidence for an elevation in overall cortical metabolism in the temporal cortex in these hemiparkinsonians could be related to the relative selectivity of this effect, with averages across the temporal region not adequately representing such a potential change.

In the basal ganglia, this correlational pattern had some similar features to that in the temporal lobe. Neuropsychological measures demonstrated negative correlations with glucose metabolism, reflecting perhaps cholinergic hyperactivity in response to dopaminergic failure. Interestingly however, these negative correlations were limited to visuospatial measures, confirming earlier assertions that the basal ganglia play an important role in visuospatial abilities. ${ }^{51}$ The one exception to these findings, verbal memory (Logical Memory) which was positively associated with glucose metabolic rates in the caudate was an isolated observation with unclear functional significance.

Selective impairment in specific memory and visuospatial function thus appears to be a consistent feature even of early or lateralized Parkinsonism. The relative lack of lateralization in neuropsychological function and glucose metabolism in cortex suggests that side to side differences in these patients affect principally extrapyramidal motor function and tend not to include higher cortical function.

\section{REFERENCES}

I. Morris RG, Downes JJ, Sahakian BJ, et al. Planning and spatial working memory in Parkinson's disease. J Neurol Neurosurg Psychiatry 1988; 51: 757-766.

2. Brown RG, Marsden CD. Neuropsychology and cognitive function in Parkinson's disease: an overview. In: Marsden CD, Fahn S, eds. Movement Disorders 2, London: Butterworths 1987; 99-123.

3. Mohr E, Fabbrini G, Ruggiere S, Fedio P, Chase TN. Cognitive concomitants of dopamine system stimulation in Parkinsonian patients. J Neurol Neurosurg Psychiatry 1987; 50: 1192-1196.

4. Mohr E, Fabbrini G, Williams J, et al. Dopamine and memory function in Parkinson's disease. Mov Disord 1989; 4: 113-120.

5. Brown R, Marsden C. Visuospatial function in Parkinson's disease. Brain 1986; 109: 987-1002.

6. Taylor AE, Saint-Cyr JA, Lang AE. Frontal lobe dysfunction in Parkinson's disease. Brain 1986; 109: 845-883.

7. Brown RG, Marsden CD. Subcortical dementia: the neuropsychological evidence. Neuroscience 1988; 25: 363-387.

8. Brown RG, Marsden CD. An investigation of the phenomenon of "Set" in Parkinson's disease. Mov Disord 1988; 3: 152-161.

9. Mohr E, Juncos J, Cox C, et al. Selective deficits in cognition and memory in high functioning Parkinson's patients. J Neurol Neurosurg Psychiatry 1990; 53: 603-606.

10. Boller F, Passafiume D, Keefe N, et al. Visuospatial impairment in Parkinson's disease: role of perceptual and motor factors. Arch Neurol 1984; 41: 485-490.

11. Mortimer JA, Pirozzolo FJ, Hansch EC, Webster DD. Relationship of motor symptoms to intellectual deficits in Parkinson disease. Neurology 1982; 32: 133-137.

12. Flowers KA, Pearce I, Pearce JMS. Recognition memory in Parkinson's disease. J Neurol Neurosurg Psychiatry 1984; 47: 1174-1181.
13. Taylor AE, Saint-Cyr JA, Lang AE. Memory and learning in early Parkinson's disease: evidence for a "frontal lobe syndrome". Brain Cogn; In Press.

14. Weingartner H, Burns S, Diebel R, LeWitt PA. Cognitive impairments in Parkinson's disease: distinguishing between effortdemanding and automatic cognitive processes. Psychiatry Res 1984; 11: 223-235.

15. Hoehn MM, Yahr MD. Parkinsonism: onset, progression and mortality. Neurology 1967; 17: 427-442.

16. Martinez AJ, Utterback RA. Unilateral Parkinson's disease, clinical and neuropathologic findings: a case report. Neurology 1973; 23: 164-170.

17. Barolin GS, Bernheimer H, Hornykiewicz O. Seitenverschiedenes Verhalten des Dopamins im Gehirn eines Falles von Hemiparkinsonismus. Schweiz Arch Neurol Psychiatr 1964; 94: 241248.

18. Huber SJ, Freidenberg DL, Shuttleworth EC, Paulson GW, Clapp LE. Neuropsychological similarities in lateralized parkinsonism. Cortex 1989; 25: 461-470.

19. Blonder LX, Gur RE, Gur RC. The effects of right and left hemiparkinsonism on prosody. Brain Lang 1989; 36: 193-207.

20. Spicer KB, Roberts RJ, LeWitt A. Neuropsychological performance in lateralized parkinsonism. Arch Neurol 1988; 45: 429432.

21. Direnfeld LK, Albert ML, Volicer L, et al. Parkinson's disease: the possible relationship of laterality to dementia and neurochemical findings. Arch Neurol 1984; 41: 935-941.

22. Zetusky WJ, Jankovic J. Laterality and symptom association in Parkinson's disease. Arch Neurol 1985; 42: 1132.

23. Garnett ES, Nahmias C, Fimau G. Central dopaminergic pathways in hemiparkinsonism examined by positron emission tomography. Can J Neurol Sci 1984; 11: 174-179.

24. Martin WRW, Stoessl AJ, Adam MJ, et al. Positron emission tomography in Parkinson's disease: glucose and dopa metabolism. Arch Neurol 1986; 45: 95-98.

25. Fahn S, Marsden CD, Calne DB, Goldstein M. Recent developments in Parkinson's disease, New Jersey: Macmillan Health Care Information 1987: 293-304.

26. Wechsler D. Wechsler Adult Intelligence Scale-Revised, New York: The Psychological Corporation 1981.

27. Wechsler D, Stone CP. Wechsler Memory Scale, New York: The Psychological Corporation 1945.

28. Mattis $S$. Mental status examination for organic mental syndrome in the elderly. In: Bellack L, Karasu TB, eds. Geriatric Psychiatry, New York: Grune and Stratton 1976: 77-121.

29. Heaton RK. A Manual for the Wisconsin Card Sorting Test, Odessa: Psychological Assessment Resources, Inc. 1981.

30. Kapur N, Butters N. Visuoperceptive deficits in long-term alcoholics and alcoholics with Korsakoff's psychosis. J Stud Alcohol 1977; 38: 2025-2035.

31. Benton, AL, Hamsher KD. Multilingual Aphasia Examination, Iowa City: University of lowa Press 1976.

32. Mosaics Comparison Test. In: Comparative Guidelines and Placement Programs, New Jersey: College Entrance Examination Board, ETS 1972.

33. Raven JC. Guide to Using the Coloured Progressive Matrices, London: HK Lewis 1965.

34. Money JA. Standardized Road Map of Direction Sense, San Rafael, CA: Academic Therapy Publications 1976.

35. Osterrieth PA. Le test de copie d'une figure complexe: contribution l'etude de la perception et de la memoire. Archives de Psychologie 1944; 30: 206-365.

36. Rey A. L'examen psychologique dans les cas d'encephalopathie traumatique. Archives de Psychologie 1941: 286-340.

37. Woodcock RWL, Johnson BW. Woodcock-Johnson Psychoeducational Battery, Boston: Teaching Resources Corp. 1977.

38. Beck AT, Ward CH, Mendelson M, Mock J, Erbaugh J. An inventory for measuring depression. Arch Gen Psychiatry 1961; 4: $561-571$.

39. Foster NL, Chase TN, Fedio P, et al. Alzheimer's disease: focal cortical changes shown by positron emission tomography. Neurology 1983; 33: 961-965. 
40. Brooks RA, Sank VJ, Di Chiro G, Friauf WS, Leighton SB. Design of a high resolution positron emission tomograph: the neuroPET. J Comput Assist Tomogr 1980; 4: 5-13.

41. Brooks RA, Friquf WS, Sank VJ, et al. Initial evaluation of a high resolution Positron Emission Tomograph. In: Greitz T, Ingvar DH, Widen L, eds. The Metabolism of the Human Brain Studied with Positron Emission Tomography, New York: Raven Press 1985: 57-68.

42. Aquilonius SM, Eckernas SA. A Colour Atlas of the Human Brain, New York: Raven Press 1980.

43. Brooks RA. Alternative formula for glucose utilization using labeled deoxyglucose. J Nucl Med 1982; 23: 538-539.

44. Freedman M, Oscar-Berman M. Selective delayed response deficits in Parkinson's and Alzheimer's disease. Arch Neurol 1986; 43: 886-890.

45. Gotham AM, Brown RG, Marsden CD. 'Frontal' cognitive functions in patients with Parkinson's disease 'on' and 'off' levodopa. Brain 1988; 111: 299-321.
46. Brown RG, Marsden $C D$. Internal versus external cues and the control of attention in Parkinson's disease. Brain 1988; 111: 323345.

47. Starkstein S, Leiguarda $R$, Gershanik O. Berthier $M$. Neuropsychological disturbances in hemiparkinson's disease. Neurology 1987; 37: 1762-1764.

48. Trasy D. Interactions between acetylcholine and dopamine in the basal ganlia. In: Davis KL, Berger PA, eds. Brain Acetylcholine and Neuropsychiatric Disease, New York: Plenum Press 1979: 395-424.

49. Hornykiewicz O, Kish SJ. Biochemical pathophysiology of Parkinson's disease. Adv Neurol 1986; 45: 19-34.

50. Lloyd $\mathrm{KG}$, Hornykiewicz $\mathrm{O}$. Occurrence and distribution of aromatic acid (L-dopa) decarboxylase in human brain. J Neurochem 1972; 19: 1549-1559.

51. Mohr E, Brouwers P, Claus JJ, et al. Visuospatial cognition in Huntington's disease. Mov Disord 1991; 6: 127-132. 